\title{
Effect of salinity and inoculation with Azosprillium on carbohydrate production, nitrogen status and yield of barley
}

\author{
A. R. Bagheri \\ Department of agronomy, Islamic Azad University, Eghlid branch, Eghlid, Iran. E-mail: aliagrono@yahoo.com. Tel: 0098- \\ 711-730-3763 or 0098-917-309-8493.
}

Accepted 27 June, 2011

\begin{abstract}
In order to evaluate the effect of Azosprillium brasilense inoculation on common barley grown in saline condition, a greenhouse experiment was conducted in Azad University, branch of Eghlid, Iran. The experimental design was a factorial based on complete randomized design with four replications. The first factor comprised of four saline water treatments ( 1 as control, 5,10 and $15 \mathrm{ds} \mathrm{m}^{-1}$ ) and the second factor included two Azosprillum inoculation levels (inoculated and uninoculated $=$ control). The measured parameters were chlorophyll fluorescence, photosynthesis (Ps) rates, carbohydrates, nitrate, ammonium and protein content, nitrogenase activity, yield and yield components. The results showed that salinity decreased plant height and grain yield (GY) in all levels. GY reduction in the inoculated treatment was lower (12.9\%) than that in the uninoculated treatment $(29.7 \%)$. It can be concluded that by plant height reduction, source efficiency reduced which caused reduction of grain number and grain weight and consequently, reduced GY. It was also observed that grain number was more susceptible to salinity than ear per meter square. Inoculation reduced harmful effects of salinity especially on mean kernel weight and grain number. There was higher starch content in inoculated treatments in comparison with uninoculated one under salinity. Fructan level increased and sucrose level decreased by inoculation, but the upward trend was seen in both traits under salinity. There was high relation between fructan content and photosynthesis rate. The mean values of Fv/Fm and photosynthesis rate reduced in the salinity treatments when compared with the control. Inoculation significantly increased photosynthesis rates at all salinity levels. The highest plant $\mathbf{N}$ content was obtained from inoculated treatment in non-saline condition. In the inoculated barley roots, nitrogenase activity (NA) was not severely inhibited by salinity. Generally, inoculation caused plant to cope with stress effectively by increasing fructan content and $\mathrm{NO}_{3} / \mathrm{NH}_{4}$ ratio and decreased less the whole plant $\mathrm{N}$ content and Fv/Fm ratio.
\end{abstract}

Key words: $\mathrm{NaCl}$, dry matter, photosynthesis, root inoculation.

\section{INTRODUCTION}

During the course of salt stress, accumulation of compatible solutes such as carbohydrates is claimed to be an effective stress tolerance mechanism (Hazewaga et al., 2000). Among the soluble carbohydrates, sucrose and fructans have potential role in adaptation to the stress (Keles and Oncel, 2004). Sucrose prevents structural changes in soluble proteins and membrane. Fructan is considered to play a key role in stress induced metabolic processes and membrane stability via liposome prevention (Krepesi and Galiba, 2000). Salinity also causes losses in grain yield (Basu and Nautyial, 2004); number of ears per meter square and number of kernels per ear (Ozturk and Aydin, 2004) and kernel weight (Pervaiz et al., 2002). Eugene et al. (1994) found that salinity may have different effects on yield and protein content. Salinity also affects $\mathrm{N}$ assimilation in plants (Katerji et al., 2000). The increasing cost of $\mathrm{N}$ fertilizers and the danger of increasing soil salinity suggest a tendency to further limitation of $\mathrm{N}$ application in rangelands (Mohammed et al., 1989). Hence, the importance of biological fixation of nitrogen increased during the past years (Ribaudo et al., 2001). Azospirillum has been 
reported to improve growth and nitrogen assimilation of cereals even under drought stress (Hamdia et al., 2000; El-Komy et al., 2003). Azospirillum inoculation can diminish the adverse effects caused by osmotic stress such as reduction of leaf senescence as well as fresh and dry weight (Pollock et al., 2002). Azospirillum inoculation under salinity and drought stress enhanced growth and mineral uptake when compared with nontreated plants (El-Komy et al., 2003). These investigations indicated that the positive role of Azospirillum could be associated with its effect on an enhancement of root nitrogenase (NA) activity (Ribaudo et al., 1998). Little information is available on nitrogenase (NA) activity of salt stressed non-legumenous plants, especially when they are inoculated. Therefore, the aim of this investigation was to study the effect of Azosprillium brasilense on photosynthesis, growth, nitrogen nutrition and nitrogenase activity of barley plants in greenhouse experiment under salt stress conditions.

\section{MATERIALS AND METHODS}

A greenhouse experiment was conducted at Agric. Exp. Stn. of Azad university, branch of Eghlid, Iran $\left(34^{\circ} 7^{\prime} \mathrm{N}\right.$ and $\left.54^{\circ} 3^{\prime} \mathrm{E}\right)$, during the years 2009 and 2010. A. brasilense strain was grown in malate medium supplied with $0.2 \mathrm{~g} \mathrm{l}^{-1}$ yeast extract for $20 \mathrm{~h}$ at $30^{\circ} \mathrm{C}$ on a shaker at $200 \mathrm{rpm}$. Cells were harvested at the logarithmic phase by centrifugation, washed twice in sterile demineralized water and then used as inoculum at the amount of $1 \mathrm{~cm}^{3}=107 \mathrm{CFU}$ per seed. Barley seeds (Hordeum vulgare L.) were surface sterilized by an immersion for $3 \mathrm{~min}$ in a mixture of $96 \%$ ethanol and $95 \% \mathrm{H}_{2} \mathrm{O}_{2}$ $(1: 1, \mathrm{~V} / \mathrm{V})$. Then, they were washed with sterile distilled water several times and germinated in the dark on wet sterile filter paper in Petri dishes for 3 days at $22^{\circ} \mathrm{C}$. Eight germinated seeds were transplanted into a pot containing $10 \mathrm{~kg}$ soil. Soil structure was clay loam. At the beginning of the second week after sowing, plants were thinned down to three per pot. The experiment comprised of four water salinity treatments to achieve soil salinities (1 as control, 5,10 and $15 \mathrm{ds} \mathrm{m}^{-1}$ ) in field capacity. Second factor included two levels of inoculation with Azosprillum (inoculated and uninoculated = control). The experimental design was a factorial based on complete randomized design with four replications. Irrigation was carried out when the soil moisture content reached $90 \%$ of F.C. Saline treatments started after plant emergence. The saline solution was made up of $\mathrm{NaCl}$ and water which were mixed in appropriate tank and the concentration requited for each salinity level were calculated and added to water. Number of ears plant ${ }^{-2}$ and grain number ear-1 were measured in the maturity stage. After harvesting and oven drying, biological and grain dry weight were measured.

\section{Chemical analysis}

\section{Chlorophyll fluorescence}

The data recorded for F0, Fm and Fv/Fm for chlorophyll fluorescence was taken $4 \mathrm{~cm}$ from the base of the abaxial surface of the primary tiller's flag leaf using a portable fluorometer (model SF-20, Richard Branker Research Ltd., Ottama, England) in both normal and late sown environments at post anthesis stage. Measurements were taken on three randomly selected plants in each plot.

\section{Analysis of photosynthesis}

Measurements of barley photosynthesis (Ps) rate was recorded from the flag leaf and the undefoliated leaf on the primary stem on each plant using a portable photosynthesis meter system (model LI6400; Li-Cor, England) at $1200 \mu \mathrm{mol}$ photons $\mathrm{m}^{-2} \mathrm{~s}^{-1}$ light intensity, $400 \mu \mathrm{mol} \mathrm{mol-1} \mathrm{CO}_{2}$, reference concentration at a constant flow of $500 \mu \mathrm{mol} \mathrm{s}^{-1}$. Data were recorded when the system was considered stable (that is, photosynthesis changes were $<0.1 \mu \mathrm{mol} \mathrm{m}-{ }^{2} \mathrm{~s}-1$ and

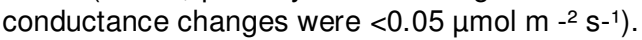

\section{Carbohydrates, nitrate, ammonium and protein content}

Water-soluble carbohydrates content at anthesis were quantified in $80 \%$ ethanol extracts of stem and leaf tissues according to the method demonstrated by Keles and Oncel, 2004. A sample of $0.1 \mathrm{~g}$ of freeze-dried flag leaf was shaken in $10 \mathrm{ml} 80 \%(\mathrm{v} / \mathrm{v})$ ethanol. The absorbance at $625 \mathrm{~nm}$ was determined with a spectrophotometer (model RF-15LL, Electronic industry Ltd., Iran). For sucrose measurement, samples were hydrolyzed by boiling in $0.1 \mathrm{M} \mathrm{HCl}$ for $60 \mathrm{~min}$. Sucrose was measured by sucrose kit. For fructan, the sample was placed in water bath at $40^{\circ} \mathrm{C}$ for $30 \mathrm{~min}$; fructan was measured by light absorption at $600 \mathrm{~nm}$.

Total $\mathrm{N}$ content in the plant dry shoots was determined after Kjeldahl digestion and the total $\mathrm{N}$ yield was calculated according to Rennie (1980). Soluble proteins were measured according to Lowry et al. (1951). Nitrate and ammonium were determined in water plant extract according to the flame photometric method (Williams and Twine, 1960).

\section{Nitrogenase activity}

Nitrogenase activity was determined for inoculated and uninoculated plants. The acetylene reduction assay (ARA) was applied according to Turner and Gibson (1980) using a gas chromatography ATIUNICAM 610- GLC (UK) equipped with a glass column backed with activated alumina. ARA was performed after 24 $\mathrm{h}$ incubation period with $10 \%$ acetylene. Results were expressed as nmol (C2H4) $\mathrm{h}^{-1} \mathrm{~g}^{-1} \mathrm{FW}$.

\section{RESULTS}

\section{Yield and yield components}

Salinity decreased GY in all the levels (Table 1). GY reduction in inoculated treatment was lower than that in the uninoculated treatment. GY was also higher in the inoculated treatment in nonsaline condition (1.36 $\mathrm{g}^{-1}$ plant). GY reduction was highly related to the reduction of grain number $(\mathrm{GN})$ rather than reduction in ear $\mathrm{m}^{-2}$, which showed approximately upward trend. It was also observed that salinity decreased mean kernel weight. Inoculation reduced harmful effects of salinity especially on mean kernel weight and grain number. Salinity also decreased crop height and ear length, which were lower in the uninoculated treatments. It can be concluded that by plant height reduction, radiation and photosynthesis efficiency reduced which caused reduction of GN and grain weight and consequently reduced GY. It was also observed that grain number was more susceptible to salinity than ear per meter square. 
Table 1. Effect of $\mathrm{NaCl}$ and inoculation on barley yield components.

\begin{tabular}{cccccccc}
\hline $\begin{array}{c}\text { Salinity } \\
\left(\mathbf{d s}^{-1} \mathbf{m}\right)\end{array}$ & In & $\begin{array}{c}\text { GY }(\mathbf{g} \\
\left.\text { plant }^{-1}\right)\end{array}$ & $\begin{array}{c}\text { Grain number } \\
\text { ear }^{-1}\end{array}$ & $\begin{array}{c}\text { EL } \\
(\mathbf{c m})\end{array}$ & $\begin{array}{c}\mathbf{1 0 0 0} \mathbf{G W} \\
\mathbf{( g )}\end{array}$ & $\begin{array}{c}\text { PH } \\
(\mathbf{c m})\end{array}$ & $\begin{array}{c}\text { Ear number } \\
\text { plant }^{-1}\end{array}$ \\
\hline \multirow{2}{*}{1} & + & $1.36^{\mathrm{a}}$ & $32.84^{\mathrm{a}}$ & $14.91^{\mathrm{a}}$ & $41.34^{\mathrm{a}}$ & $82.5^{\mathrm{a}}$ & $4.05^{\mathrm{a}}$ \\
& - & $0.621^{\mathrm{c}}$ & $17.2^{\mathrm{c}}$ & $12.86^{\mathrm{bc}}$ & $35.21^{\mathrm{b}}$ & $69.59^{\mathrm{c}}$ & $3.90^{\mathrm{a}}$ \\
& & & & & & & \\
& & & & & & & \\
15 & + & $1.07^{\mathrm{b}}$ & $26.23^{\mathrm{b}}$ & $13.49^{\mathrm{b}}$ & $40.29^{\mathrm{a}}$ & $76.47^{\mathrm{b}}$ & $4.20^{\mathrm{a}}$ \\
& - & $0.336^{\mathrm{d}}$ & $11.79^{\mathrm{d}}$ & $11.34^{\mathrm{c}}$ & $30.85^{\mathrm{c}}$ & $66.035^{\mathrm{c}}$ & $3.83^{\mathrm{a}}$ \\
\hline
\end{tabular}

Means with the same letter in each column and treatment are not significantly different at probability level of $5 \%$ (Duncan). In = inoculated with Azusprillium; GY = grain yield; $\mathrm{EL}=$ ear length; $1000 \mathrm{GW}=1000$ grain weight; $\mathrm{PH}=$ plant height.

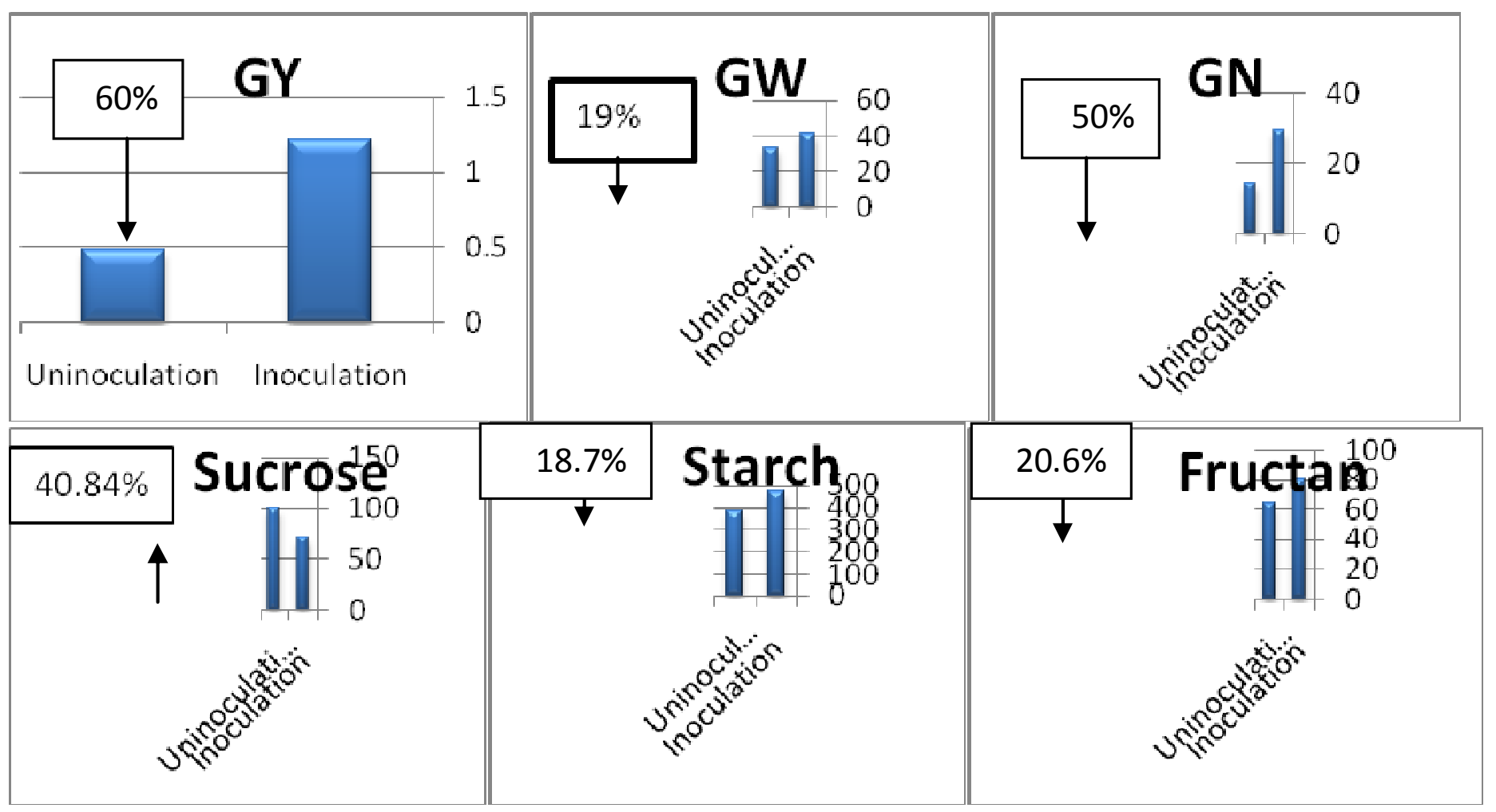

Figure 1. Comparison of inoculated and uninoculated barley plants in yield and carbohydrate content (GY: grain yield, GW: grain weight and GN: grain number per plant).

On the other hand, the plant tended to preserve ear number per plant under salinity. Inoculated treatments showed $60 \%$ lower decrease in GY compared with uninoculation treatments (Figure 1). It was also observed that $\mathrm{GN}$ reduction rate was lower in the inoculated treatments. Therefore, the plant grain yield could be preserve from salinity injury by inoculation treatments.

\section{Carbohydrates content}

Table 2 shows the total shoot saccharides and protein content. There was higher starch content in the in- oculated treatments in comparison with the uninoculated one under salinity $\left(435.0 \mathrm{mg} \mathrm{g}^{-1} \mathrm{DW}\right.$ and $340.0 \mathrm{mg}$, respectively). According to Figure 1, inoculation caused plant to maintain 18.7 starch more than the control. Soluble saccharides increased by salinity. Inoculation, significantly changed shoots soluble saccharide content in plants by different trends. Fructan level increased and sucrose level decreased by inoculation (20.6 and $40.84 \%$, respectively according to Figure 1). There were high negative correlation between sucrose and fructan content with grain yield $\left(r^{2}=-0.96^{* *}\right.$ and $-0.85^{\star *}$, respectively) and positive correlation between grain yield and starch content $\left(r^{2}=0.89^{\star \star}\right)$. 
Table 2. Effect of $\mathrm{NaCl}$ and inoculation on carbohydrates and protein content.

\begin{tabular}{cccccc}
\hline Salinity $\left(\mathbf{d s}^{-1}\right)$ & Inoculation & Starch $\left(\mathbf{m g ~ g}^{-1}\right)$ & Sucrose $\left(\mathbf{m g ~ g}^{-1}\right)$ & Fructan $\left(\mathbf{m g ~ g}^{-1}\right)$ & Protein $\left(\mathbf{m g ~ g}^{-1}\right)$ \\
\hline \multirow{2}{*}{1} & + & $505.0^{\mathrm{a}}$ & $66.45^{\mathrm{d}}$ & $67.83^{\mathrm{b}}$ & $73.89^{\mathrm{a}}$ \\
& - & $424.5^{\mathrm{b}}$ & $90.85^{\mathrm{b}}$ & $57.0^{\mathrm{c}}$ & $74.75^{\mathrm{a}}$ \\
\multirow{2}{*}{15} & & & & & \\
& + & $435.0^{\mathrm{b}}$ & $76.32^{\mathrm{c}}$ & $92.5^{\mathrm{a}}$ & $71.7^{\mathrm{b}}$ \\
\hline
\end{tabular}

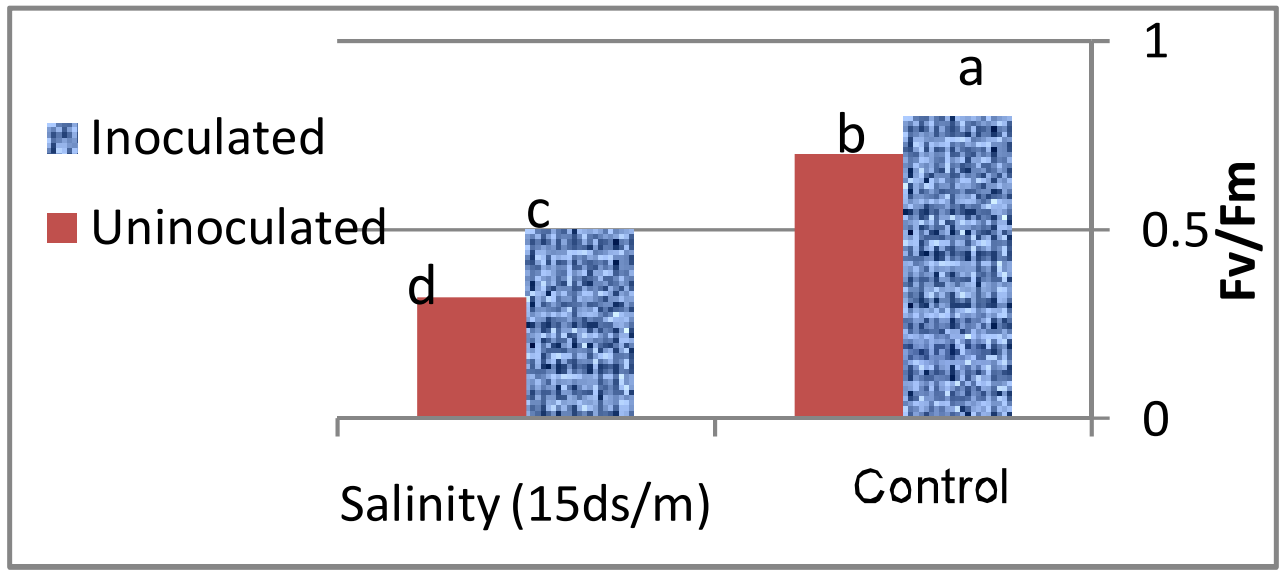

\begin{tabular}{|l|l|}
\hline \multicolumn{2}{|l|}{ Percent of Fv/Fm reduction } \\
\hline Un-inoculation & Inoculation \\
\hline 57.1 & 32.5 \\
\hline
\end{tabular}

Figure 2. Effect of salinity on Fv/Fm ratio under inoculation treatment.

These correlations were more visible in inoculated plants than in the uninoculated ones. The spectacular result of saccharide measurements in this study, according to Table 2 was that in inoculated plants, increase in fructan levels was the defense strategy against enhancing salinity, but uninoculated plants, increased sucrose content to cope with the stress.

\section{Chlorophyll fluorescence photosynthesis}

The mean values of $\mathrm{Fv} / \mathrm{Fm}$ variable fluorescence (Figure 2) reduced the salinity treatments compared with the control. It was observed that the magnitude of $\mathrm{Fv} / \mathrm{Fm}$ differences differed with a wide range among the inoculation treatments in both saline and non-saline conditions. The $\mathrm{Fv} / \mathrm{Fm}$ value reduction in high salinity level $(15 \mathrm{ds} / \mathrm{m})$ was $32.5 \%$ in the inoculated treatments and $57.1 \%$ in the uninoculated one (Figure 1). It reveals that energy production I photosynthetic light reaction possibly reduced especially in the saline and uninoculated treatments.

Photosynthesis rates decreased with the increase of salinity (Figure 3). Inoculation significantly increased photosynthesis rates (Figure 3). Inoculation did not affect photosynthesis rate in the control salinity treatment, but significantly influenced photosynthetic rate in high salinity condition. As it is shown, in high salinity level and uninoculated treatment, the photosynthesis reduction was $68 \%$ of the control, whereas in high salinity level in inoculated treatment the reduction was $40 \%$.

Our results indicate that salinity condition was responsible for appreciably altering the source activity with a decrease in photosynthetic capacity. In addition, we did 


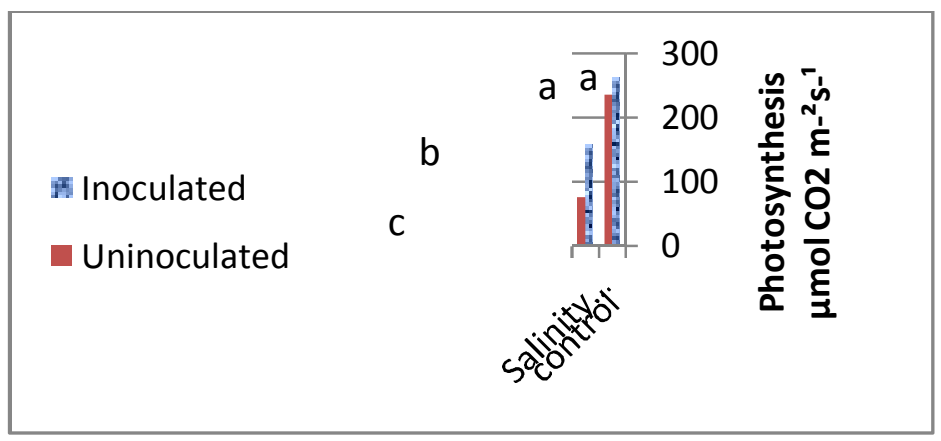

\begin{tabular}{|c|c|}
\hline \multicolumn{2}{|c|}{ Percent photosynthesis rate reduction } \\
\hline Un-inoculation & Inoculation \\
\hline 68 & 40 \\
\hline
\end{tabular}

Figure 3. Effect of salinity on photosynthesis rate under inoculation treatment.

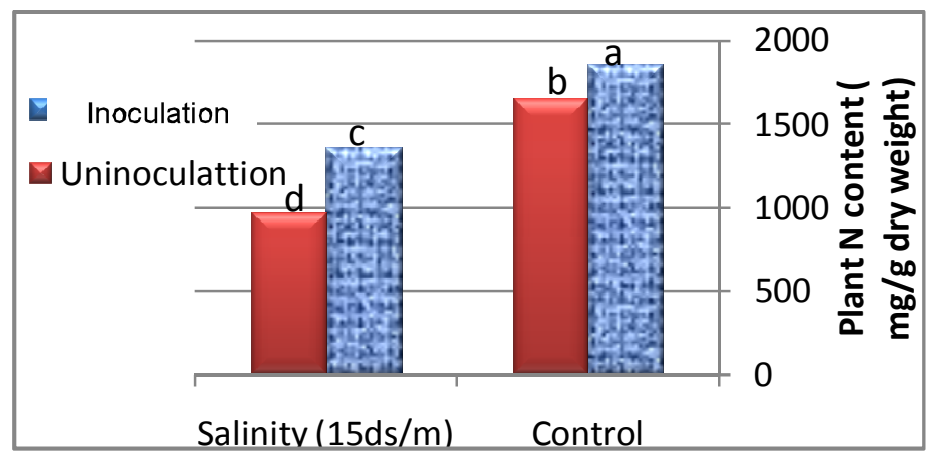

\begin{tabular}{|c|c|}
\hline \multicolumn{2}{|c|}{ Percent of N content reduction } \\
\hline Un-inoculation & Inoculation \\
\hline 40.6 & 27 \\
\hline
\end{tabular}

Figure 4. Interaction effects of salinity, inoculation treatment and Mo application on plant $\mathrm{N}$ content.

observe a significant decrease in source leaf stomatal conductance (data are not shown). It indicates that carboxylation efficiency and ribulose 1,5-bisphosphate regeneration may have been decreased. Decrease in photosynthetic capacity might be related directly to stomatal dynamics. It was also marvelous that by increasing salinity, Fv/Fm ratio, which showed the efficiency of Psll, showed lower reduction rate in inoculated treatments compared with the uninoculated ones (Figure 2).
Plant $\mathrm{N}$ content, nitrate/ammonium ratio, nitrogenase activity and protein content

The highest plant $\mathrm{N}$ content was obtained from inoculated plants in the control salinity treatment and the lowest $\mathrm{N}$ content was observed in high salinity treatment without inoculation (Figure 4). On the other hand, the plant $\mathrm{N}$ reduction under salinity was lower (approximately 27\%) in the inoculated treatment, whereas in the uninoculated treatment in salinity, plant $\mathrm{N}$ content reduced by $40.6 \%$. 
A

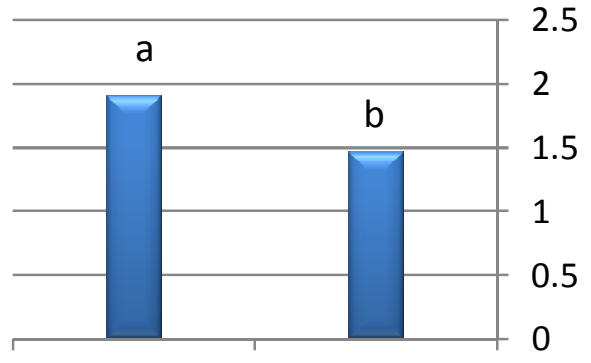

Uninoculation Inoculation

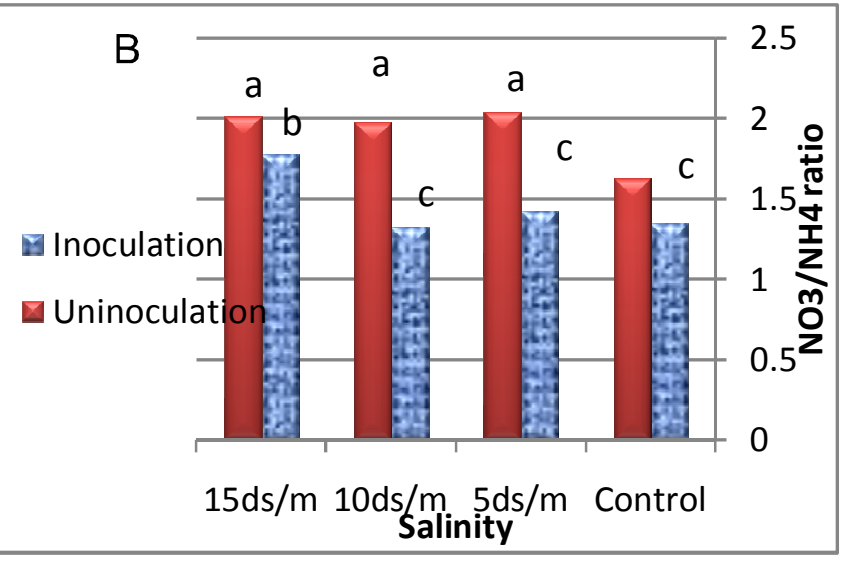

$15 \mathrm{ds} / \mathrm{m} 10 \mathrm{ds} / \mathrm{m}$ Salinity $5 \mathrm{ds} / \mathrm{m}$ Control

Figure 5. Effects of salinity and inoculation treatment on $\mathrm{NO}_{3} / \mathrm{NH}_{4}$ ratio. a, Interaction effect; b, simple comparison.
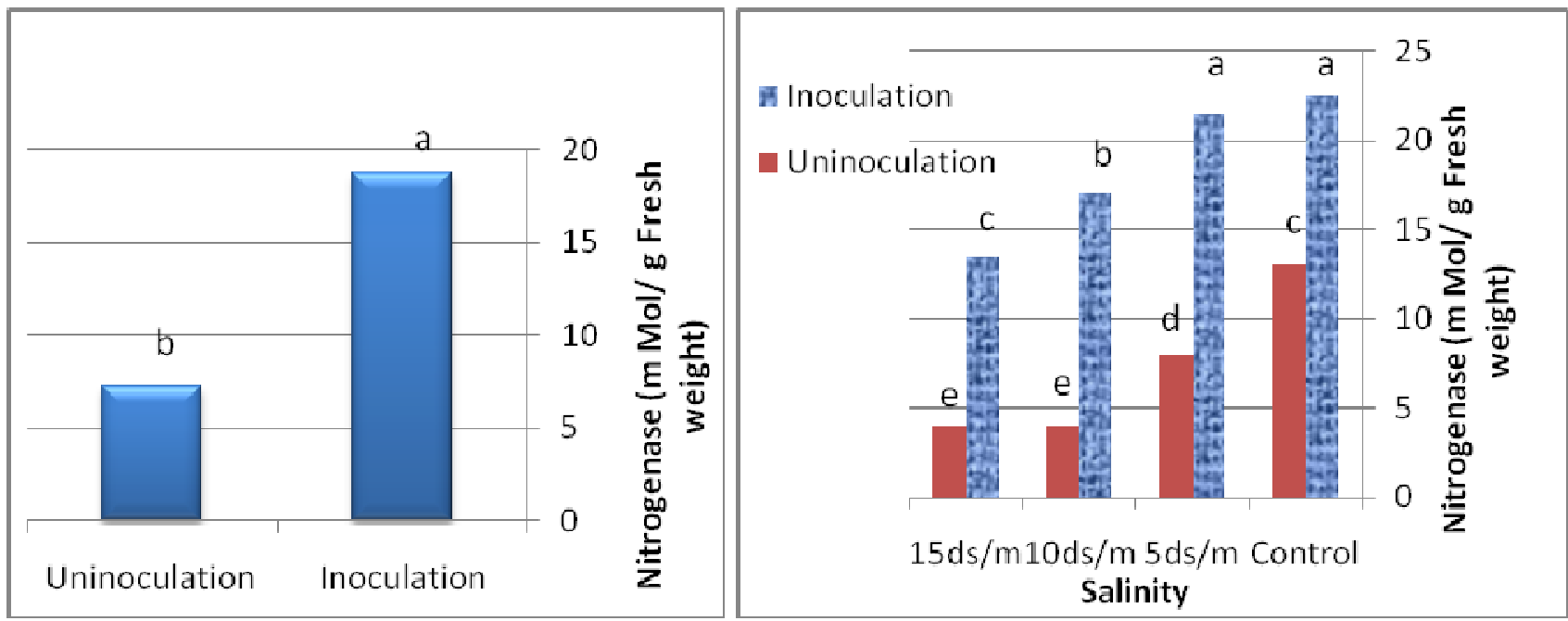

Figure 6. Effects of salinity and inoculation on nitrogenase activity.

Nitrate/ammonium ratio in shoots increased as the salinity increased (Figure 5). Treatment with Azospirillium, primarily prevented the nitrate accumulation up to 10 $\mathrm{ds} / \mathrm{m}$ salinity, but promoted the accumulation of nitrate and increased $\mathrm{NO}_{3} / \mathrm{NH}_{4}$ ratio in high salinity. The lowest $\mathrm{NO}_{3} / \mathrm{NH}_{4}$ ratio was obtained from nonsaline, inoculated treatments (1.25) and the highest ratio was observed in $15 \mathrm{ds} / \mathrm{m}$ and uninoculated treatment.

In the inoculated barley roots, nitrogenase activity (NA) was severely inhibited by salinity (Figure 6 ). In the control treatment, nitrogenase activity was $23 \mathrm{mg}^{-1} \mathrm{~g} \mathrm{FW}$, whereas in 10 and $15 \mathrm{ds} / \mathrm{m}$, it reached $4 \mathrm{mg}^{-1} \mathrm{~g} \mathrm{FW}$. Uninoculated plants showed higher decrease in NA activity compared with the respective inoculated plants. The unexpected NA activity in the uninoculated treatment was due to the pre experiment existence of Azospirillium in the soil. NA activity in the inoculation treatments was $18 \mathrm{mg}^{-1} \mathrm{~g}$ FW and in the uninoculated treatment it was only $7 \mathrm{mg}^{-1} \mathrm{~g} \mathrm{FW}$. Also, as it was seen, there was no significant different in NA activity up to $5 \mathrm{ds} / \mathrm{m}$ in the inoculated treatments.

Unexpectedly, salinity did not highly affect the protein content (Table 2). Although the highest plant $\mathrm{N}$ content was observed in the inoculated treatment under salinity condition, but the lowest protein content was obtained in this treatment.

\section{DISCUSSION}

Progressive increase in soil salinity up to $15 \mathrm{ds} \mathrm{m}^{-1}$ induced changes in the nitrogen metabolism of barley. Plant dry weight and total $\mathrm{N}$-yield appeared to be inhibited drastically by the increase of salinity. This inhibition was associated with a decline in nitrogenase activity (NA) in roots of barley plants. Similar results have 
been reported by several investigations (Masepohi et al., 1993; Peuke et al., 1996; Abd El-Backi et al., 2000; ElKomy et al., 2003). These authors reported that NA activity was affected negatively by the increase of salt stress intensity. It could be suggested that evaluating the stimulatory effect of bacterial inoculation on barley growth and nitrogen fixation would be profitable in this condition. One of the main mechanisms of the recorded barley growth promotion is directly related to the capability of Azospirillum sp. to produce growth promoting substances (IAA, IBA) as well as its nitrate reductase activities, as reported by Failik et al. (1994), Okon and LabanderaGonzales (1994) and Hamdia and El-Komy (1998). Generally, salinity decreased nitrogen fixation and reduced $\mathrm{NH}_{4}$ content of barley therefore, crop energy expenditure would be increased, additionally, photosynthesis was decreased. It was also observed that $\mathrm{Fv} / \mathrm{Fm}$ ratio, which shows the efficiency of photosystems, decreased and it was expected that by inefficient activation of feredoxin, $\mathrm{N}$ reduction process of barley became inefficient (Taize and Zeiger, 2006). Reduction of growth rate, photosynthesis and storage carbohydrates caused reduction of grain yield. This has been proved by other investigators (Basu and Nautyial, 2004). A decline in nitrogenase activity(NA) of Azospirillium inoculated or an uninoculated plant was indicated as a result of the salinity injury. There is an evidence which indicates that inoculation not only increases the specific NA activity, but also enhances the extended period of high NA activity and further inclusion of ammonia into organic compounds (through glutamine synthetase activity) compared with the control (Pollock et al., 2002). Under experimental conditions, one of the marvelous results of this study was that in the inoculated plants, the tolerance mechanics was to increase the fructan level and preserve more starch from break down processes. It was reported that fructan could protect membrane liposomes and enhance membrane stability (Keles and Uncel, 2004) and it could be the confirmation of higher photosystem efficiency which relates directly to the thylakoid membrane status. So, it can be concluded that inoculation could promote salt tolerance by preserving the membrane flexibility. But in the uninoculated plants, salinity forced the plant to increase sucrose content and cope with the stress by osmoregulation.

\section{Conclusion}

Increase in salinity, declined nitrogenase activity (NA) in roots and nitrogen content of barley plants. It reduced $\mathrm{NH}_{4}$ content of barley, therefore, crop energy expenditure would be increased, despite, it could have some profits for the plant. In the inoculation treatments which increased plant stress tolerance, increase in nitrate/ ammonium ratio was inhibited as much as possible. Therefore, it prevented toxic effects of nitrate accumulation in the cell. Plant respond to salinity processes by starch break down and sucrose (in untreated plants) and fructan (in inoculated plants) accumulation. Increase in fructan content caused increase in membrane stability and ensured membrane related processes. The evidence of this hypothesis is the increase in photosystems efficiency (Fv/Fm ratio) which is highly related to the membrane health of the thylakoid. Salinity caused reduction of growth rate, photosynthesis and storage carbohydrates led to the reduction of grain yield. This could be attributed to the decrease in grain number or grain weight. Since in this experiment, barley grew in continuous stress situation and could acclimate with that condition, the constant grain weight was expected (in spite of a little reduction in severe stress condition). It was also observed that ear number per plant did not reduce in salinity. As this component was formed in early growth stages, it can be concluded that the inoculation treatments, could have reduced the harmful effects of salinity in the early growth stages and their benefits reduced as the plant grow longer. Generally, since inoculation enhanced plant tolerance, and these differences in tolerance are related to fructan accumulation, it could be concluded that fructan accumulation is a safer mechanism in stress tolerance than sucrose accumulation.

\section{REFERENCES}

Abd El-Baki GK, Siefritz F, Man HM, Weiner H, Kaldenhoff R Kaiser WM (2000). Nitrate reductase in Zea mays L. under salinity. Plant Cell Environ. 23: 515- 521.

Basu MS, Nautiyal PC (2004). Improving water use efficiency and drought tolerance in groundnut by trait based breeding in India. Ind. Farm, 54: 24-27.

El-Komy MH, Hamdia MA, Abd El-Baki GK (2003). Nitrate reductase in wheat plants grown under salinity and inoculated with Azospirillum spp. Biol. Plant, 46: 281-287.

Failik E, Sarig S, Okon Y (1994). Morphology and physiology of root associated with Azospirillum /plant associations. Edited-by Okon CRC Press, Bioca Raton Gla, pp.77-85.

Hamdia MA, El-Komy MH (1998). Effect of salinity, gibberellic acid and Azospirillum inoculation on growth and nitrogen uptake of Zea mays. Biol. Plant. 40: 109-120.

Hamdia MA, El-Komy MH, Barakat N (2000). The role of foliar and potassium fertilization and /or $\mathrm{p}$ Azospirillium lipoforum or Bacillus polymexa inoculation in nitrogen fixation and mineral nutrition of maize grown under salt stress. 8th Int. Colloq. Optimiz. Plant Nutr. April. 8- 13.Cairo Sheraton, Cairo-Egypt. p. 193.

Hazewaga, P, Bressan RA, Zu J K, Bohnert J (2000). Plant cellular and molecular response to high salinity. Ann. Rev. Plant Physiol. 51: 463499.

Keles Y, Oncel I (2004) Growth and solute composition on two wheat species experiencing combined influence of stress conditions. Russ. J. Plant Physiol. 51:203-208.

Krepesi I, Galiba G (2000). Osmotic and salt stress-induced alteration in soluble carbohydrate content in wheat seedlings. Crop Sci. 40: 482487.

Lowry OH, Roserbrough NJ, Fail AL, Randall RJ (1951). Protein measurements with folin phenol reagent. J. Biol. Chem. 193: 265275.

Masepohl B, Kry R, Klipp W (1993). The draTG gene region of Rodobactor capsulatus is a requirement for post-translational regulation of both the molybdenum at the alternative nitrogenase. J. Gen. Microbiol. 139: 2667-2675. 
Mohammed M, Campbell WF, Rumbaugh MD (1989) Variation in salt tolerance of alfalfa. Arid Soil Rehabil. 3: 11-20.

Okon A, Labanadera-Gonzales CA (1994) Agronomic application of Azospirillum. An Evaluation of 20 years worldwide field inoculation. Soil Biol. Biochem. 26: 591-601.

Ozturk A, Aydin F (2004). Effect of water stress at various growth stages on some quality characteristics of winter wheat. J. Agron. Crop Sci. 190:93-99.

Peuke AD, Glaab J, Kaiser WD, Jeschke WD (1996). The uptake and flow of $\mathrm{C}, \mathrm{N}$ and ions between roots and shoots in Ricinus communis. IV. Flow and metabolism of inorganic $\mathrm{N}$ and malate depending on nitrogen nutrition and salt treatment. J. Exp. Bot. 47: 377-385.

Pollock VV, Conover RC, Johnson MK, Barber MJ (2002). Bacterial expression of the molybdenum domain of assimilate nitrate reductase: Production of both the functional and nonfunctional molybdenum-containing domain. Arch. Biochem. Biophys. 2: 237248.

Pervaiz Z, Afzal M, Xi S, Xiaoe Y, Ancheng L (2002). Physiological parameters of salt tolerance in wheat. Asian J. Plant Sci 1:478-481.

Rennie RJ (1980). 15N- isotop dilution as a measure of nitrogen fixation by Azospirillum brasilense associated with maize. Can. J. Bot. 58: 2124.
Ribaudo CM, Paccusse AN, Cura JA, Frascina AA (1998). Azospirillum maize association: effects on yield and nitrate reductase activity. Agric. Trop. Subtrop. 31: 61-70.

Ribaudo CM, Rondanini DP, Cura JA, (2001). Response of Zea mays to the inoculation with Azospirillum on nitrogen metabolism under greenhouse conditions. Biol. Plant, 44: 631-634.

Taiz L, Zeiger E (2006). Plant physiology. Sinauer associated Inc.4th Edn. p690.

Turner GLK, Gibson AH (1980). Measurement of nitrogen fixation by indirect means. In: Bergersen, FJ (ed): Methods for Evaluating Biological Nirtogen Fixation. John Willey \& Sons, New York. pp. 111138.

Williams V, Twine S (1960). Flame photometeric method for sodium, potassium, and calcium. In: Paech K, Tracey MV (eds): Modern Methods of plant Analysis. Springer-Veralg, Berlin, 5: 3-5. 